\title{
REPENSAR EL MODELO: UNA PROPUESTA PARA JUGAR CON/EN EL SISTEMA DEL ARTE
}

\author{
Oihane Sánchez Duro \\ Universidad del País Vasco / Euskal Herriko Unibertsitatea, Dpto. Arte y Tecnología, Doctoranda
}

\section{Resumen}

Con el impulso de las políticas culturales que se desarrollan en occidente desde la década de los 70 , se estructura un modelo cultural cada vez más homogéneo. Este modelo, acentuado por una visión instrumentalista de la cultura, repercute sobre el tejido cultural local. Las características del mismo promueven un escenario en el que otros formatos y expresiones artístico-culturales encuentran dificultades para perdurar. Interpelados por las problemáticas que devienen de un modelo rígido y acotado, cabe abordar nuevas propuestas desde el arte como medio para profundizar en los intersticios del sistema con el objetivo de proponer posibles alternativas, opciones de resistencia, disidencia o integración.

\section{Palabras-clave:CULTURA; MODELO; MONOCULTIVO; ECOSISTEMA; HACK}

\section{RETHINK THE MODEL: A PROPOSAL TO PLAY WITH/WITHIN THE ART SYSTEM}

\section{Abstract}

Driven by the cultural policies that have been developed in the West since the 70 s, an increasingly homogeneous cultural model is being shaped. This model, marked by an instrumentalist vision of culture, has an impact on the local cultural environment. It functions in a way that means other artistic-cultural formats and expressions find it difficult to persist. Questioning the issues that arise from a rigid and limited model, we can address new proposals through art as a tool to delve into the interstices of the system in order to suggest possible alternatives, ways of resistance, dissidence or integration.

Keywords: CULTURE; MODEL; MONOCULTURE; ECOSYSTEM; HACK

\footnotetext{
Sánchez Duro, Oihane. 2018. "Repensar el modelo: Una propuesta para jugar con/en el sistema del arte”. AusArt 6 (2): 79-91. D0I:10.1387/ ausart.20352
}

\section{AUSART}




\section{INTRODUCCIÓN}

Este documento establece una aproximación a las características del modelo cultural hegemónico que se asienta en occidente desde la década de los 70 hasta la actualidad, y su repercusión sobre el tejido cultural local ${ }^{1}$. El objetivo de este artículo es distribuir y analizar las características de dicho modelo en una serie de capas que, en su conjunto, forman la estructura del sistema cultural oficial. La metodología ha seguido el desarrollo de una propuesta plástica: la identificación de las distintas características y su disposición en capas, sugería un tipo de formato que nos permite reconocer visualmente la organización del sistema cultural occidental, como veremos más adelante.

Entendemos sistema oficial del arte como resultado del modelo de gestión cultural dominante que se desarrolla en las sociedades occidentales. Durante el texto, nos referiremos a este sistema como a su gestión bajo la denominación 'modelo cultural oficial', desde el que se establece la forma de entender y hacer en cultura.

Situamos como punto de partida las políticas culturales que se desarrollan en Europa occidental desde la década de los 70, las cuales influyen en los distintos países europeos y sus regiones.

[...] organismos internacionales como la UNESCO o el Consejo de Europa organizaron, sobre todo desde finales de los sesenta, reuniones y conferencias en diferentes partes del mundo en las que se abordó la espinosa tarea de saber qué se entendía por cultura. También se reflexionaba ya sobre los modos de llevar a cabo una planificación cultural mundial que tuviera en cuenta la específica situación social, política, cultural y económica de países ubicados en diferentes continentes. Por lo tanto, lo novedoso de ese tema es la apuesta por parte de la UE de asumir competencias en el ámbito de la cultura.

(Méndez 2004, 17)

Tal y como recogen investigadoras como Lourdes Méndez (2004) o Maider Zilbeti (2016), Europa cuenta con un importante patrimonio y numerosa obra plástica heredada del pasado; un periodo en el que los estados buscan construir una identidad propia a través de la cultura. Así, la acción de las políticas culturales europeas se divide en tres ejes: "La conservación/restauración del patrimonio artístico/cultural; la ayuda a la creación de nuevos productos cultu- 
rales, y la difusión social de la cultura desde la premisa de la democratización cultural" (Méndez 2004, 43).

De este modo, se suceden grandes inversiones económicas para dotar las ciudades europeas de la infraestructura necesaria para el acceso a la cultura y la difusión de la misma. Cabe destacar que las inversiones no están dirigidas a la obtención de beneficios económicos a corto y medio plazo, sino a la acumulación del capital simbólico suficiente que favorezca la distinción entre ciudades europeas:

Atendiendo el recorrido de las políticas culturales en el contexto de la Unión Europea en la década de 1980, en torno a la producción de artes plásticas y el patrimonio, los distintos países europeos realizan grandes inversiones en museos e infraestructura. Aunque en un primer momento no obtengan grandes beneficios económicos de este tipo de infraestructuras y macro-proyectos, apuestan por el beneficio simbólico que pueden obtener de los mismos².

(Zilbeti 2016, 44)

Coincidiendo con el auge del turismo cultural, esto último también promueve la competición entre las diferentes ciudades europeas en la arena internacional: mediante la promoción y explotación de su patrimonio cultural, tratan de posicionarse como el destino turístico más atractivo:

Por lo tanto, en la década de 1990, la línea que desarrollan las políticas culturales es la de seducir las inversiones económicas. [...] las infraestructuras culturales, la compra de obras, y también los grandes dispositivos que se organizan en torno a éstas (festivales, bienales...) aunque requerían grandes inversiones de dinero público, eran justificadas por el discurso de que más tarde revertirían en beneficios económicos ${ }^{3}$.

(lbíd.)

Muchos de los proyectos que se llevan a cabo en la Comunidad Autónoma Vasca (CAV) responden a este modelo cultural y su gestión; las políticas culturales de la CAV son recíprocas a "[...] un fenómeno global influido por varios factores (el auge del neocapitalismo y el desarrollo del turismo global, entre otros) y que ha afectado a cada zona" ${ }^{4}$ (Barcenilla 2016, 30). Debido a la relación que se establece entre cultura e intereses políticos y económicos, prevalecen unos formatos sobre otros en menoscabo de otras expresiones culturales. 
Como hemos adelantado anteriormente, nos referiremos a esta homogeneización como 'monocultivo cultural' ya que las consecuencias inherentes a priorizar modelos concretos debilitan el ecosistema cultural local.

\section{EL MONOCULTIVO CULTURAL Y SUS CONSECUENCIAS}

Tomamos el concepto de 'monocultivo', perteneciente al campo de la agricultura ${ }^{5}$, a fin de trasladarlo al ámbito de la cultura para aludir a la priorización de unos elementos y formatos hegemónicos. Precisamente, uno de los aspectos más significativos del monocultivo es su incompatibilidad con la diversidad del medio en el que se sitúa, debido a las características intrínsecas que lo perfilan como un organismo que funciona al margen de un ecosistema mayor. Esta separación o dificultades para integrarse en un ecosistema, se debe a que el monocultivo supone en sí un modelo a importar y reproducir en lugares que compartan en mayor o menor medida las mismas condiciones para garantizar su desarrollo.

De hecho, en Glosario imposible (Querol, Villa \& Fox 2018), el artista Javier Montero se remite a David Harvey (2005) para definir un modelo que "obsesionado con la estabilidad y estabilizar, ha estructurado este territorio como un espacio mediado, normatizado, regulado, instrumentalizado, homogeneizado. De hecho, ha utilizado todos los medios a su alcance para tratar de establecer una cultura hegemónica" (citado en Montero 2018, 200)

Así, las consecuencias del mismo han sido agrupadas en capas interrelacionadas:

La base sobre la que se asienta dicho modelo tiene su origen en las políticas culturales que se perfilan en el contexto anglosajón, como hemos adelantado en la introducción. Principalmente, la cultura supone un motor para la regeneración económica de ciudades desindustrializadas. Desde la cultura, se trata de reproducir un formato que revierte en legitimación política, económica y simbólica de sus gestores en el tránsito hacia un arquetipo de ciudad basado en la cultura y el sector servicios. Del mismo modo, la cultura se convierte en un elemento indispensable de la industria del ocio y el entretenimiento. Sin embargo, el ecosistema cultural local se resiente: la precariedad es una cons- 
tante en la actividad profesional de los artistas, los productores y los agentes culturales del propio entorno.

A continuación, profundizaremos en las características del monocultivo cultural.

\subsection{LAS CAPAS DEL SISTEMA}

\subsubsection{La capa cero: la cultura como legitimación política y económica}

La crisis económica que sobreviene con el colapso del modelo de producción industrial impulsa la necesidad de encontrar reactivadores económicos que reviertan el declive. A finales del siglo $\mathrm{XX}$ y con el avance de los gobiernos neoliberales, la cultura empieza a desplazarse hacia el centro de la economía. En Nuevas economías de la cultura (2009) el colectivo YProductions remite a una serie de factores que propician esta relación:

Este paradigma empezará a encontrar su lugar en Europa a finales de los 70s y a lo largo de los 80s con la llegada al poder de políticas de austeridad neoliberales, cuyas tesis encontraron eco como fórmula para superar la crisis que empezaron a padecer los Estados de Bienestar a partir de 1973. Desde mediados de los 80s y principios de los 90s, toda una serie de fenómenos interrelacionados acaban por situar al conocimiento en el centro de la economía...

(YProductions 2009, 10)

Por este motivo, distintos países intentarán medir y regular las bases económicas de un nuevo sector que aglutina toda índole de productos artísticos y culturales, considerados tradicionalmente al margen del sistema económico (Echeverría 2014). Entre otros, podemos mencionar las llamadas industrias culturales como un ejemplo de la unión entre productos culturales y el mercado.

Entre otras estrategias que tienen su origen a principios de la década de los 90 , asistimos a otro fenómeno en el que las ciudades industriales en declive optan por poblar el entramado urbano de contenedores culturales de alto presupuesto con el fin de recuperar y estetizar áreas urbanas degradadas. Sin ir más lejos, la apertura del museo Guggenheim de Bilbao en 1997 es un buen ejemplo de esto último: la instalación de este emblemático equipamiento cultu- 
ral en una zona baldía pero céntrica de dicha ciudad ha promovido la transformación del lugar y sus áreas vecinas.

Por citar algunos ejemplos, a principios de los 2000 tiene lugar la puesta en marcha de numerosos museos tanto en Europa como en el estado español. Entre otros, la Tate Modern de Londres inicia su andadura ese mismo año; el museo Reina Sofía de Madrid en 2001; el Museo Picasso de Málaga en 2003, y el MUSAC (museo de arte contemporáneo) de León en 2005.En la CAV se inaugura el museo Artium en 2003 en Vitoria-Gasteiz, y poco después se aborda el proyecto KREA Expresión Contemporánea en esta misma localidad, aunque nunca llegó a ponerse en marcha. En 2004 se inicia el proyecto cultural Tabakalera en Donostia-San Sebastián y se consolida entre 2015 y 2016 , coincidiendo con la capitalidad cultural de la ciudad.

\subsubsection{La capa uno: el modelo de la ciudad cultural}

La transición hacia el modelo de la ciudad cultural se apoya en la explotación del patrimonio cultural de la misma (por ejemplo, a través de sus contenedores culturales emblemáticos como los apuntados en el apartado en el anterior), generando el valor distintivo necesario para atraer tanto grandes masas de visitantes como inversiones tanto públicas como privadas.

De hecho, George Yúdice define la cultura como un medio para la inversión: "El papel de la cultura se ha expandido de una manera sin precedentes al ámbito político y económico, al tiempo que las nociones convencionales de cultura han sido considerablemente vaciadas" $(2002,23)$.

Junto con los contenedores culturales de alto presupuesto, proliferan los grandes eventos dirigidos al gran público, como las bienales de arte, los festivales de música y cine, etc. Habitualmente, este tipo de formatos se aglutinan bajo el paraguas internacional, a fin de favorecer la movilidad de visitantes de distintos países.

En los 90, en un contexto de aceleración de los procesos de globalización y del uso de la cultura como recurso, [...] se experimentará un boom de grandes eventos (bienalización del arte) y la apertura del museo Guggenheim-Bilbao marcará el inicio de un cambio de paradigma cultural a nivel internacional, ampliamente criticado y caracterizado por la instrumentalización del arte (pro- 
ducto de consumo, motor de la economía, etc.) a través de grandes equipamientos-empresa.

(Jaio 2009)

Como vemos, podemos hablar de modelo de ciudad cultural cuando la cultura se implica en el desarrollo urbano (Carrillo 2008a, 5). Esto último nos lleva a preguntarnos por el papel que desempeña la cultura en los procesos de construcción de una imagen o branding de ciudad, en la que tanto su patrimonio, los productos culturales y simbólicos como sus productores se presentan como proveedores de nuevas y exclusivas experiencias.

\subsubsection{La capa dos: la cultura como espectáculo}

Se trata de reproducir un patrón que parece funcionar. Además, se impulsan distintas propuestas dentro del ámbito cultural que generen cierta diferenciación con el equipo de gobierno anterior.

Si bien el inicio de nuevos proyectos en el ámbito cultural puede parecer algo deseable, una de las consecuencias es que puede obstaculizar la perdurabilidad de otras iniciativas, o desembocar en su completa paralización. Como concreta Barcenilla $(2016,40)$ :

La homogeneización, por lo tanto, consiste en promover desde la política una única imagen de la cultura, unificada y vendible, relacionada con el ocio y no con la reflexión, el debate, la experimentación o la diversidad. Para conseguirlo, el sistema de ayudas y subvenciones se ha blindado en torno a unos proyectos estratégicos ${ }^{6}$.

Al mismo tiempo, prevalecen la forma y contenidos a importar, y cuyos resultados han resultado positivos en otras ciudades: el objetivo es obtener el mayor rendimiento (económico, político y mediático) a través de la cultura.

Un ejemplo lo encontramos en la mención de Capital Europea de la Cultura, título que ostentan una o dos ciudades de Europa durante un año. Durante este tiempo, la ciudad escogida organiza una exhaustiva programación cultural dirigida a la ciudadanía en general. En la CAV, Donostia-San Sebastián recibió dicha distinción en 2016, organizándose en este año más de 3.000 actividades ${ }^{7}$. 


\subsubsection{La capa tres: resultados inmediatos en detrimento de procesos prolongados}

Por una parte, se trata de eventos que destacan por la retribución de beneficios a corto plazo: entre otros, cabe destacar el impacto económico y mediático de los mismos.

Por otra parte, y relacionado con esto último, Barcenilla adelanta que el éxito de este tipo de formatos genera recelo hacia otros espacios más independientes o iniciativas experimentales, dirigidas a un público minoritario:

"[...] la crisis económica de los últimos años ha demostrado que es demasiado costoso mantener grandes infraestructuras. Los grandes eventos puntuales se han convertido en su sustituto, como la capitalidad cultural de Donostia San Sebastián [...] que acarrea varias consecuencias negativas. La primera, aunque no sea la más evidente, es generar recelo hacia las prácticas experimentales ${ }^{8}$.

(Ibíd.,41)

Además, los productores locales suelen tener una escasa participación en los eventos macro. Normalmente, contar con cierta visibilidad, queda sujeto al sistema de ayudas de carácter concursal, generando una gran competencia entre creadores y agentes culturales. Asimismo, la "cultura del proyecto" promueve los resultados predecibles frente a procesos más extendidos, Barcenilla relaciona la competitividad con la precarización del sector, algo muy en la línea de las políticas del sistema neocapitalista basadas en la instrumentalización y explotación de las artes para crear imágenes. Según la propia Barcenilla (Ibíd.,42), estas mismas políticas culturales, no van nunca encaminadas a la búsqueda de soluciones para la mejora de la situación, lo que provoca que los creadores queden subordinados a los sistemas de subvenciones.

\subsubsection{La capa cuatro: precariedad del ecosistema cultural local}

Los distintos proyectos culturales que se suceden, así como los formatos y contenidos globalizados que se importan y reproducen, no surgen como respuesta a las problemáticas a las que se enfrentan los artistas, productores y agentes culturales locales, y son pocas las garantías para la perdurabilidad de diferentes expresiones artísticas y culturales:

Las políticas controlan cada vez más la imagen de la cultura: atraer al turista medio, ofrecer una ciudad limpia, moderna y global, 
cómoda y silenciosa. Ello conlleva apartar otro tipo de prácticas no acordes con esa imagen, pero aceptadas hasta el momento, como se ha visto en los casos de Kukutza y Kortxoenea. En el caso de Kortxoenea, el cierre se ejecutó la misma semana que abría Tabakalera, presentando dos alternativas culturales complementarias como contrapuestas e incompatibles" 9.

(Barcenilla 2016, 42)

Como consecuencia, las iniciativas que divergen de lo oficialmente establecido, se desarrollan habitualmente en condiciones de precariedad y vulnerabilidad, desapareciendo progresivamente del mapa. Este es el caso de los espacios auto-gestionados como los que hemos señalado en el párrafo anterior: los gaztetxes ${ }^{10}$ son espacios culturales autogestionados vinculados al contexto (social, cultural) del lugar en el que se ubican. Son además, un elemento constante en nuestro paisaje cultural.

Nos interesa mencionar dicho ejemplo ya que una de las características comunes de los gaztetxes es que se tratan de espacios que han estado largamente en desuso (viejas fábricas, almacenes, edificios industriales,...) y que son okupados por un grupo de personas que ponen en marcha un proyecto socio-cultural con la intención de dar respuesta a una serie de necesidades del propio lugar. Además, aunque la gestión se realiza con pocos recursos económicos, la programación que desarrollan resulta sostenible en el tiempo, realizando una aportación constante al ámbito social y cultural cercano.

\subsection{Hacks para repensar el modelo}

Si bien podemos pensar en este tipo de espacios y otras iniciativas culturales como pequeños rescoldos de resistencia frente a los formatos hegemónicos, cabe preguntarnos si es posible la disidencia desde la propia práctica en arte: ¿cómo llevar a cabo los gestos, las acciones que permitan ahondar entre las grietas del sistema y proponer otras alternativas?

El objetivo de la propuesta que se describe a continuación es el de pensar colectivamente formas de desestabilizar las jerarquías estancas, encontrar fisuras y proponer posibles alternativas frente a un modelo cerrado.

Así, nace la Barahacker'11 (contracción de las palabras 'baraja' y 'hacker'), un juego de cartas pensado como medio para abordar problemáticas comunes sobre nuestro entorno socio-cultural cercano. Como adelantábamos en 
la introducción, se trata de una propuesta plástica que permite visualizar la estructura del sistema o modelo cultural oficial que hemos descrito en los apartados anteriores.

La disposición de la baraja muestra las capas que forman el citado modelo, compuestas a su vez por cartas que recogen las diferentes características del mismo a través de la combinación de texto e imagen. La mecánica del juego consiste en desarticular esta jerarquía: conforme las cartas se van desvelando por orden, los asistentes deben proponer otras alternativas en relación a la problemática que muestra la carta.

Estas respuestas son en sí mismas una serie de hacks ${ }^{12}$, que permite cuestionar el funcionamiento del modelo cultural vigente. Además de pensar colectivamente otras formas de jugar con o en el sistema del arte, los hacks que integran la Barahacker forman, en sí, una invitación a la acción.

\section{CONCLUSIONES}

La reproducción sistemática de modelos concretos conlleva una serie de consecuencias que influyen en el tejido cultural local. En Reflexiones y propuestas sobre los nuevos centros de creación contemporánea (2008), Jesús Carrillo recoge algunas sugerencias a asumir por las instituciones en materia de cultura, a fin de mitigar la lógica capitalista que envuelve este ámbito.

En el mismo documento, Carrillo aboga por un modelo cultural que asuma el carácter ecosistémico del contexto social y cultural existente con el fin de facilitar una mayor cohesión e integración en el entorno y los agentes que trabajan en el mismo,

[...] y no intentar cubrir indiscriminadamente y a modo de monopolio todo aquello 'que se mueve' y puede caer bajo el apelativo de cultura, [...] Es por ello fundamental que parta de las dinámicas internas del lugar, evitando tanto el efecto 'ovni' como el de 'caballo de Atila' y que no se entienda este lugar ni como una reserva cultural que rentabilizar turísticamente, ni como un territorio que sanear y transformar de un modo sistemático.

(Carrillo 2008) 
Podemos establecer un vínculo entre esta perspectiva ecosistémica y la postura del hacker, la cual plantea una nueva ética del trabajo y las relaciones de poder capitalistas (Himanen 2004).

En nuestro caso, podríamos trasladar la figura del hacker al artista o el agente cultural que recoge esta visión de ecosistema en relación al ámbito cultural en el que se inserta, y que opta por la creación de redes (y relaciones) mutuas de apoyo, difusión e intercambio.

Al inclinarse por formatos próximos a lo común, lo colectivo o lo colaborativo, tanto el hacker como el artista (o el artista hacker), cuestionan los modelos establecidos; profundizan en sus capas buscando modos de hacer más sostenibles ${ }^{13}$.

\section{Referencias}

Barcenilla García, Haizea. 2016. “Kultur politikak: Paradigma aldaketa?”Jakin 215-216

Carrillo Castillo, Jesús. 2008a. "Las nuevas fábricas de la cultura: Los lugares de la creación y la producción cultural en la España contemporánea". Biblioteca YP. http://ayp.unia.es/spip/ IMG/pdf/Jesus_Carrillo_nuevas_fabricas_de_la_cultura.pdf.

Carrillo Castillo, Jesús. 2008b. "Reflexiones y propuestas sobre los nuevos centros de creación contemporánea". Descargable en "Laboratorio del procomún: Nuevos centros de creación contemporánea", Ecosistemaurbano.org (blog), 21 feb. https://ecosistemaurbano.org/eventos/laboratorio-del-procomun-nuevos-centros-de-creacion-contemporanea/

Echeverría Ezponda, Javier. 2014. "Estructura del sector cultural y creativo y problemas para analizarlo en el País Vasco". En Áreas emergentes e innovación en el sector cultural y creativo vasco, editores, Andrea Estankona, Arantza Lauzirika, Natxo Rodríguez. Bilbao: Universidad del País Vasco

Harvey, David. 2005. A brief history of neoliberalism. London: Oxford University

Himanen, Pekka. 2004. La ética del hacker y el espíritu de la era de la información. Prólogo de Linus Torvalds; epílogo de Manuel Castells; traducción de Ferran Meler Ortí. Barcelona: Destino

Jaio Atela, Miren Terese. 2009. "Tout va bien / Garai txarrak: Una mirada a treinta años de historia". Gara-Mugalari, 30 oct.

Méndez Pérez, Lourdes. 2004. Galicia en Europa: El lugar de las artes plásticas en la política cultural de la Xunta. A Coruña: Castro

Montero, Javier. 2018. "Puntos de fuga”. En Glosario imposible, edición, Miriam Querol, Álvaro Villa, Jonathan Fox; traductores, Toni Crabb et al. Madrid: Hablarenarte 
Montero, Javier, Núria Güell \& María Ruido. 2018. “Agentes”. En Glosario imposible, edición, Miriam Querol, Álvaro Villa, Jonathan Fox; traductores, Toni Crabb et al., 195-213. Madrid: Hablarenarte

Querol, Miriam, Álvaro Villa \& Jonathan Fox, eds. 2018. Glosario imposible. Traductores, Toni Crabb et al., 195-213. Madrid: Hablarenarte

YProductions. 2009. "Nuevas economías de la cultura: Parte I, Tensiones entre lo económico y lo cultural en las industrias creativas". interaccio.diba.cat/sites/interaccio.diba.cat/files/ e170093.pdf

Yúdice, George. 2002. El recurso de la cultura: usos de la cultura en la era global. Traducción, Gabriel Ventureira \& Desiderio Navarro. Barcelona: Gedisa

Zilbeti Pérez, Maider. 2016. “Arte-ekoizpen feministak euskal testuinguru kulturalean: Arte-instituzio garaikideetako praktika; Arteleku Zentroa eta Montehermoso Kulturunea. Bilbo: Udako Euskal Unibertsitatea

\section{Notas}

1 En el texto mencionados reiteradamente 'tejido" o 'ecosistema cultural local'. Con ello, nos referimos a un conjunto compuesto por prácticas, expresiones e iniciativas artísticas y culturales diversas, programas y espacios tanto institucionales como independientes dedicados a la creación y/o exhibición, y una amplia comunidad de artistas, productores, agentes, gestores culturales, investigadores, etc. que trabajan en el entorno inmediato (en nuestro caso, la Comunidad Autónoma Vasca).

${ }^{2}$ Cita original:"Kultura-politikek, Europar Batasuneko testuinguruan egindako ibilbideari jarraituz, 1980ko hamarkadan, arte-plastiko ekoizpenaren inguruan eta ondarearen inguruan, hauei harrera egiteko museo eta azpiegituretan inbertsioa handiak egiten dituzte Europako herrialde ezberdinek. Nahiz eta lehendabiziko momentu batean honako azpiegitura eta proiektu erraldoiei ez dieten etekin ekonomiko garbirik ateratzen, hauengandik atera dezaketen etekin sinbolikoaren aldeko apustua egiten dute." (Zilbeti 2016, 44).

${ }^{3}$ Cita original: "Hortaz, 1990eko hamarkadan, cultura politikek garatu zuten ildoa inbertsio ekonomikoak seduzitzearena izan zen. [...] Kultura-azpiegiturek, obren erosketek, eta baita hauen inguruan antolatzen ari ziren erakusketa dispositivo erraldoiek ere (jaialdiek, bienalek,...) diru publikoaren inbertsio handia eskatzen baldin bazuten ere, gerora, ekonomikoki etekinak ekarriko zituztelako diskurtsoekin justifikatzen ziren." (ibíd.).

${ }^{4}$ Cita original: "[...] jaugin globala da, beste hainbat faktorek sakonki eragin dutena (neokapitalismoaren gorakadak eta turismo globalaren garapenak, besteak beste) eta lekuan lekuko eraginak izan dituena." (Barcenilla 2016, 30).

${ }^{5}$ Concepto perteneciente al campo de la producción agrícola que refiere al uso de grandes extensiones de tierra al cultivo de una sola especie vegetal. Ello conlleva, entre otros aspectos, el debilitamiento o el desgaste de los nutrientes presentes en el suelo, falta de diversidad, y con ello, alteraciones relacionadas con el ecosistema existente; la falta o presencia de ciertos elementos puede propiciar plagas y enfermedades, y ello acarrear el uso de fertilizantes y pesticidas químicos que constituyen una fuente de contaminación. Los monocultivos también suponen un peligro para la conservación de otros elementos autóctonos. Desde la presente investigación, utilizaremos el concepto de monocultivo como metáfora para designar el fomento de un modelo cultural hegemónico e importable, al margen del ecosistema cultural heterogéneo local ya presente. 
${ }^{6}$ Cita original:"Homogeneizazioa, beraz, politikatik hobesten den kulturaren irudi bakar, bateratu eta salgarria bultzatzean datza, aisialdiarekin lotuta eta egogoeta, eztabaida, esperimentazio edo aniztasunarekin. Hori lortzeko, diru-laguntza sistema proiektu estrategiko batzuen inguruan blindatu da." (Barcenilla 2016, 40).

${ }^{7}$ Para más información, consultar www.dss2016.eu [Acceso 26 dic. 2018].

${ }^{8}$ Cita original: "[...] azken urteetako krisi ekonomikoak azpiegitura erraldoiak mantentzea garestiegia dela erakutsi du. Horren ordezko bihurtu dira ekimen puntual handiak, Donostiako kultur hiriburutza, esaterako [...] hainbat ondorio kaltegarri dakartza. Lehena, nahiz eta ezageriena, praktika esperimentalekiko susmoa sortzea da." (Ibíd., 41).

${ }^{9}$ Cita original: "Politikek gero eta kontrolatuagoa dute kulturaren irudia: maila ertaineko turista erakartzeko, hiri garbia, modernoa eta globala eskaini nahi da, erosoa eta lasaia. Horrek irudiarekin batez datozen eta lehen onartzen ziren bestelako kultur praktikak baztertzera darama, Kukutza eta Kortxoenearen kasuetan ikusi bezala. Kortxoenean, gainera, oso modu argian burutu zen itxiera Tabakalera ireki behar zen asteberean, osagarriak diren bi kultur aukera kontrajarri eta batera ezintzat aurkeztuz." (Ibíd.).

${ }^{10}$ La palabra Gaztetxe está compuesta 'gazte' (joven) y 'etxe' (casa), pudiendo traducirse como 'casa para o de los jóvenes', quienes gestionan este tipo de espacios.

${ }^{11}$ Para más información sobre esta propuesta, ver https://vimeo.com/308310635 [Acceso 26 dic. 2018].

12 En el texto, nos referimos al 'hack' como la acción relacionada con la actividad del hacker. Encontramos similitudes entre esta acepción del 'hack' y determinadas acciones y/o posiciones desde la práctica artística y cultural.

${ }^{13}$ Asociamos el concepto de sostenibilidad con el concepto de 'tejido' o 'ecosistema cultural local' al que aludimos aquí. Esta sostenibilidad estaría ligada al desarrollo de políticas culturales que asuman las demandas y el cuidado de ese tejido o ecosistema cultural local que lleva a cabo su actividad profesional en el contexto próximo. Más que la reproducción de un modelo cultural categórico, se trataría de buscar otros 'modos' de hacer desde la gestión cultural más coherentes con los formatos y prácticas culturales existentes, de forma que pueda darse una actividad profesional estable.

(Artículo recibido: 09-11-18; aceptado: 07-01-19) 